\title{
Association of total testosterone status with bone mineral density in adults aged 40 60 years
}

Nan Wang ${ }^{1,2^{*}} \mathbb{D}$, Lixiang Wang ${ }^{1,2}$ and Chengcheng Huang ${ }^{3}$

\begin{abstract}
Objective: Evidence linking total testosterone and bone mineral density (BMD) in adults is very limited. According to our review of the literature, only a few reports have focused on the relationship between total testosterone and bone mineral density in adults. Therefore, the purpose of this study was to determine the relationship between total testosterone and total bone mineral density in adults aged $40-60$ years.
\end{abstract}

Methods: We used a cross-sectional study of a non-institutionalized U.S. population sample from the National Health and Nutrition Examination Survey. A weighted multivariate linear regression model was used to evaluate the relationship between total testosterone and total bone mineral density. Subgroup analyses were further performed.

Results: In multiple regression models adjusted for potential confounders, total testosterone levels were inversely associated with total bone mineral density. However, in the sex-stratified subgroup analysis, the association between total testosterone levels and total bone mineral density was not significant in female adolescents. There was no negative association between total testosterone and total BMD among men, adults 40 to 60 years of age, and other racial/ ethnic groups. There is a negative association between total testosterone and total bone mineral density when total testosterone concentration is greater than $500 \mathrm{ng} / \mathrm{dL}$ among Non-Hispanic black.

Conclusion: Our statistical results show that the association between total testosterone levels and total bone mineral density varies by gender and race. Elevated total testosterone levels below $500 \mathrm{ng} / \mathrm{dL}$ have adverse effects on bone health. Total testosterone concentrations below $500 \mathrm{ng} / \mathrm{dL}$ may have no effect on bone health.

Keywords: Testosterone, Bone mineral density, Adults, NHANES, Cross-sectional study

\section{Introduction}

Osteoporosis is a common clinical disease. Studies have shown that after menopause, women have lower estrogen levels, lower bone density, and develop osteoporosis. Bone mineral density was positively correlated with estrogen levels in women. However, the relationship between male osteoporosis and hormone levels is often

\footnotetext{
*Correspondence: wangnan1105@126.com

1 Department of Orthopaedics, Zhejiang Chinese Medical University

Affiliated Jiangnan Hospital, 152 Yucai Road, Chengxiang Street, Xiaoshan District, Hangzhou City 311200, Zhejiang Province, China

Full list of author information is available at the end of the article
}

ignored, and a large number of patients do not receive timely diagnosis and treatment.

As age increases, the level of Testosterone in middleaged men gradually decreases, leading to the occurrence of Testosterone deficiency. The traditional view is that male osteoporosis is similar to female osteoporosis, and sex hormone levels play an important role in regulating bone mass and metabolism. Men with hypogonadism have faster bone metabolism, an increased risk of osteoporosis and brittle fractures. Men with osteoporosis have lower testosterone levels.

Convincing experimental studies reported that bone mineral density seems to be influenced by testosterone original author(s) and the source, provide a link to the Creative Commons licence, and indicate if changes were made. The images or other third party material in this article are included in the article's Creative Commons licence, unless indicated otherwise in a credit line to the material. If material is not included in the article's Creative Commons licence and your intended use is not permitted by statutory regulation or exceeds the permitted use, you will need to obtain permission directly from the copyright holder. To view a copy of this licence, visit http://creativecommons.org/licenses/by/4.0/. The Creative Commons Public Domain Dedication waiver (http://creativeco mmons.org/publicdomain/zero/1.0/) applies to the data made available in this article, unless otherwise stated in a credit line to the data. 
levels and men's exercise [1]. The sex hormones deficit can predict the reduction of BMD in men [2]. A study population consisted of 2447 community-dwelling men in America showed that older men with total testosterone were more likely to be osteoporotic [3]. People with osteoporosis are more likely to have a total lack of testosterone. Men who are completely deficient in testosterone are more likely to lose bone rapidly. It may be clinically necessary to detect BMD in elderly men with sex hormone deficiency [4, 5].Moreover, increasing evidence supported that there is a strong link between testosterone concentration and bone mineral density $[6,7]$.

Recent epidemiological studies reported a positive association between total testosterone and BMD in the middle-aged and older men $[4,8]$. Until now, evidence linking total testosterone and BMD in men is very limited $[9,10]$. Osteoporosis in middle-aged men varies from country to country, depending on age, sex, ethnicity and region.In addition, testosterone concentration is affected by age, sex, body composition, and other factors that influence BMD [11].Therefore, we conducted a larger cross-sectional study based on the national population to determine the association between testosterone and BMD in men aged 40 to 60 years.

\section{Materials and methods}

\section{Statement of ethics}

This study was approved by the ethics review board of the National Center for Health Statistics, and written consent was obtained from each participant.

\section{Study population}

The data analyzed came from the National Health and Nutrition Examination Survey (NHANES) (2011-2016), which is a stratified, multi-stage probability sample of the uninstitutionalized U.S. population. These crosssectional surveys are conducted by the National Center for Health Statistics (NCHS). A detailed approach to NHANES is available at http://www.cdc.gov/nchs/ nhanes/.

\section{Variables}

Study subjects were limited to participants aged 40-60 years $(n=6005)$. The NCHS Ethics Review Board approved the actions of NHANES and obtained the written informed consent of all participants.

\section{Study variables}

The main variables in this study were total testosterone (independent variable) and total BMD (dependent variable).

This is a validated isotope dilution liquid chromatography tandem mass spectrometry (ID-LC-MS/MS) method for routine quantitation of serum total testosterone based on the National Institute for Standards and Technology's (NIST) reference method. Total BMD was measured by dual-energy X-ray absorptiometry.

In addition, the following covariates were included: age, sex, race/ethnicity, level of education, income-poverty ratio, total protein, serum phosphorus, and serum calcium. Detailed information about the data measurement process is available at http://www.cdc.gov/nchs/nhanes/.

\section{Statistical analyses}

All estimates were calculated accounting for NHANES sample weights. Weighted multiple regression analysis was applied to estimate the independent relationship between total testosterone and total BMD. Weighted generalized additive models and smooth curve fittings were employed to address the non-linearity of total BMD and total BMD in the subgroup analyses.

Categorical variables were expressed as frequency or percentage. Continuous variables were expressed as means \pm standard deviation. Weighted linear regression models (continuous variables) and weighted chi-square tests (categorical variables) were performed to calculate differences between different groups. $P<0.05$ was considered statistically significant. All analyses were performed with Empower software (http://www.empowerstats.com; $\mathrm{X} \& \mathrm{Y}$ solutions, Inc., Boston MA) and R version 3.4.3 (http://www.R-project.org, The R Foundation).

\section{Results}

Table 1 shows the description of weighted sociodemographic and medical characteristics of the participants. A total of 6005 participants were included in this study. Of these participants, $47.34 \%$ were male, $52.66 \%$ were female, $13.96 \%$ were Non-Hispanic white, $34.12 \%$ were Non-Hispanic black, 23.93\% were Mexican Americans, and $27.99 \%$ were other race. Total testosterone (quartiles, Q1-Q4) were significantly different groups, including age, sex, race/ethnicity, income-poverty ratio, total protein, serum phosphorus, serum calcium, and total BMD (Table 2, Figs. 1, 2, 3).

\section{Discussion}

The main findings of our study were as follows: First is the association between total testosterone levels and total bone mineral density was not significant in female adolescents. Second, there was no negative association between total testosterone and total BMD among men, adults 40 to 60 years of age, and other racial/ethnic groups when total testosterone concentration is less than $500 \mathrm{ng} / \mathrm{dL}$. Third, there is a negative association between total testosterone and total bone mineral density when total testosterone concentration is greater than $500 \mathrm{ng} /$ 
Table 1 Weighted characteristics of the study population based on total testosterone quartiles

\begin{tabular}{|c|c|c|c|c|c|c|}
\hline Testosterone total (ng/dL) & Total & Q1 & Q2 & Q3 & Q4 & $P$ value \\
\hline Age (years) & $49.9 \pm 6.1$ & $50.3 \pm 5.8$ & $49.6 \pm 6.0$ & $50.0 \pm 6.0$ & $50.2 \pm 6.2$ & 0.0148 \\
\hline Sex (\%) & & & & & & $<0.0001$ \\
\hline Male & 47.3 & 0.1 & 0.0 & 88.6 & 99.8 & \\
\hline Female & 52.7 & 99.9 & 100 & 11.4 & 0.2 & \\
\hline Race/ethnicity (\%) & & & & & & 0.0284 \\
\hline Non-Hispanic white & 14.0 & 9.7 & 6.9 & 7.5 & 8.4 & \\
\hline Non-Hispanic black & 34.1 & 63.0 & 68.2 & 67.8 & 68.2 & \\
\hline Mexican American & 23.9 & 12.2 & 12.2 & 10.5 & 10.1 & \\
\hline Other race/ethnicity & 28.0 & 15.1 & 12.7 & 14.2 & 13.4 & \\
\hline Level of education (\%) & & & & & & $<0.0001$ \\
\hline Less than high school & 23.2 & 14.1 & 13.4 & 13.5 & 18.0 & \\
\hline High school & 21.5 & 18.2 & 18.6 & 22.3 & 22.5 & \\
\hline More than high school & 55.3 & 67.7 & 68.0 & 64.3 & 59.5 & \\
\hline Income to poverty ratio & $2.7 \pm 1.7$ & $3.2 \pm 1.7$ & $3.2 \pm 1.7$ & $3.4 \pm 1.6$ & $3.2 \pm 1.7$ & 0.0106 \\
\hline Total protein (mg/dL) & $71.5 \pm 4.7$ & $70.3 \pm 4.6$ & $70.4 \pm 4.4$ & $70.8 \pm 4.5$ & $70.9 \pm 4.4$ & 0.0013 \\
\hline Serum calcium (mg/dL) & $9.4 \pm 0.4$ & $9.4 \pm 0.4$ & $9.3 \pm 0.4$ & $9.4 \pm 0.4$ & $9.4 \pm 0.3$ & 0.1272 \\
\hline Serum phosphorus (mg/dL) & $3.7 \pm 0.6$ & $3.9 \pm 0.5$ & $3.8 \pm 0.5$ & $3.7 \pm 0.6$ & $3.6 \pm 0.6$ & $<0.0001$ \\
\hline Total BMD $\left(\mathrm{g} / \mathrm{cm}^{2}\right)$ & $1.1 \pm 0.1$ & $1.1 \pm 0.1$ & $1.1 \pm 0.1$ & $1.1 \pm 0.1$ & $1.1 \pm 0.1$ & $<0.0001$ \\
\hline
\end{tabular}

Mean \pm SD for continuous variables: the $P$ value was calculated by the weighted linear regression model. (\%) for categorical variables: the $P$ value was calculated by the weighted chi-square test. BMD, bone mineral density

Table 2 The association between total testosterone $(\mathrm{ng} / \mathrm{dL})$ and total bone mineral density $\left(\mathrm{g} / \mathrm{cm}^{2}\right)$

\begin{tabular}{|c|c|c|c|c|c|c|}
\hline & \multicolumn{2}{|l|}{ Model 1} & \multicolumn{2}{|l|}{ Model 2} & \multicolumn{2}{|l|}{ Model 3} \\
\hline & $\beta(95 \% \mathrm{Cl})$ & $P$ value & $\beta(95 \% \mathrm{Cl})$ & $P$ value & $\beta(95 \% \mathrm{Cl})$ & $P$ value \\
\hline Total testosterone $(\mathrm{ng} / \mathrm{dL})$ & $0.0001(0.0001,0.0001)$ & $<0.000001$ & $0.0000(-0.0000,0.0000)$ & 0.907372 & $0.0001(0.0001,0.0002)$ & $<0.000001$ \\
\hline \multicolumn{7}{|l|}{ Total testosterone categories } \\
\hline Q1 & 0 & & 0 & & 0 & \\
\hline Q2 & $0.0067(-0.0026,0.0160)$ & 0.159252 & $0.0034(-0.0055,0.0123)$ & 0.449622 & $0.0057(-0.0035,0.0150)$ & 0.223303 \\
\hline Q3 & $0.0633(-0.0540,0.0726)$ & $<0.000001$ & $0.0023(-0.0171,0.0217)$ & 0.815594 & $0.0044(-0.0154,0.0242)$ & 0.665964 \\
\hline Q4 & $0.0775(0.0682,0.0867)$ & $<0.000001$ & $0.0104(-0.0108,0.0315)$ & 0.335823 & $0.0155(-0.0063,0.0372)$ & 0.162864 \\
\hline \multicolumn{7}{|c|}{ Subgroup analysis stratified by sex } \\
\hline Men & $0.0000(-0.0000,0.0000)$ & 0.719289 & $0.0000(-0.0000,0.0000)$ & 0.864406 & $0.0000(-0.0000,0.0000)$ & 0.36741 \\
\hline Women & $-0.0001(-0.0002,0.0001)$ & 0.492458 & $-0.0001(-0.0002,0.0001)$ & 0.270182 & $-0.0001(-0.0003,0.0000)$ & 0.151631 \\
\hline \multicolumn{7}{|c|}{ Subgroup analysis stratified by race/ethnicity } \\
\hline Non-Hispanic white & $0.0001(0.0001,0.0001)$ & $<0.000001$ & $-0.0001(-0.0001,0.0000)$ & 0.062793 & $-0.0001(-0.0001,0.0000)$ & 0.324209 \\
\hline Non-Hispanic black & $0.0001(0.0001,0.0002)$ & $<0.000001$ & $0.0000(-0.0000,0.0001)$ & 0.521033 & $0.0000(-0.0000,0.0001)$ & 0.303087 \\
\hline Mexican American & $0.0001(0.0001,0.0001)$ & $<0.000001$ & $-0.0001(-0.0001,0.0000)$ & 0.05225 & $-0.0000(-0.0001,0.0000)$ & 0.155034 \\
\hline Other race/ethnicity & $0.0001(0.0001,0.0002)$ & $<0.000001$ & $0.0000(-0.0000,0.0001)$ & 0.193526 & $0.0000(-0.0000,0.0001)$ & 0.315806 \\
\hline
\end{tabular}

Model 1: no covariates were adjusted. Model 2: age, sex, and race/ethnicity were adjusted. Model 3: age, sex, race/ethnicity, education, income poverty ratio, total protein, serum phosphorus and serum calcium were adjusted. In the subgroup analysis stratified by sex and race/ethnicity, the model is not adjusted for sex and race/ ethnicity, respectively

dL among Non-Hispanic white, Non-Hispanic black and Mexican Americans .

Low total bone mineral density is associated with an increased risk of osteoporotic fracture. The association between total testosterone and BMD received extensive research and attention over the years. In a study of 1070 Korean men, J shin et al. identified that both total testosterone and free testosterone were positively associated with BMD and that genetic effects were significant on the association between testosterone and BMD [12]. 

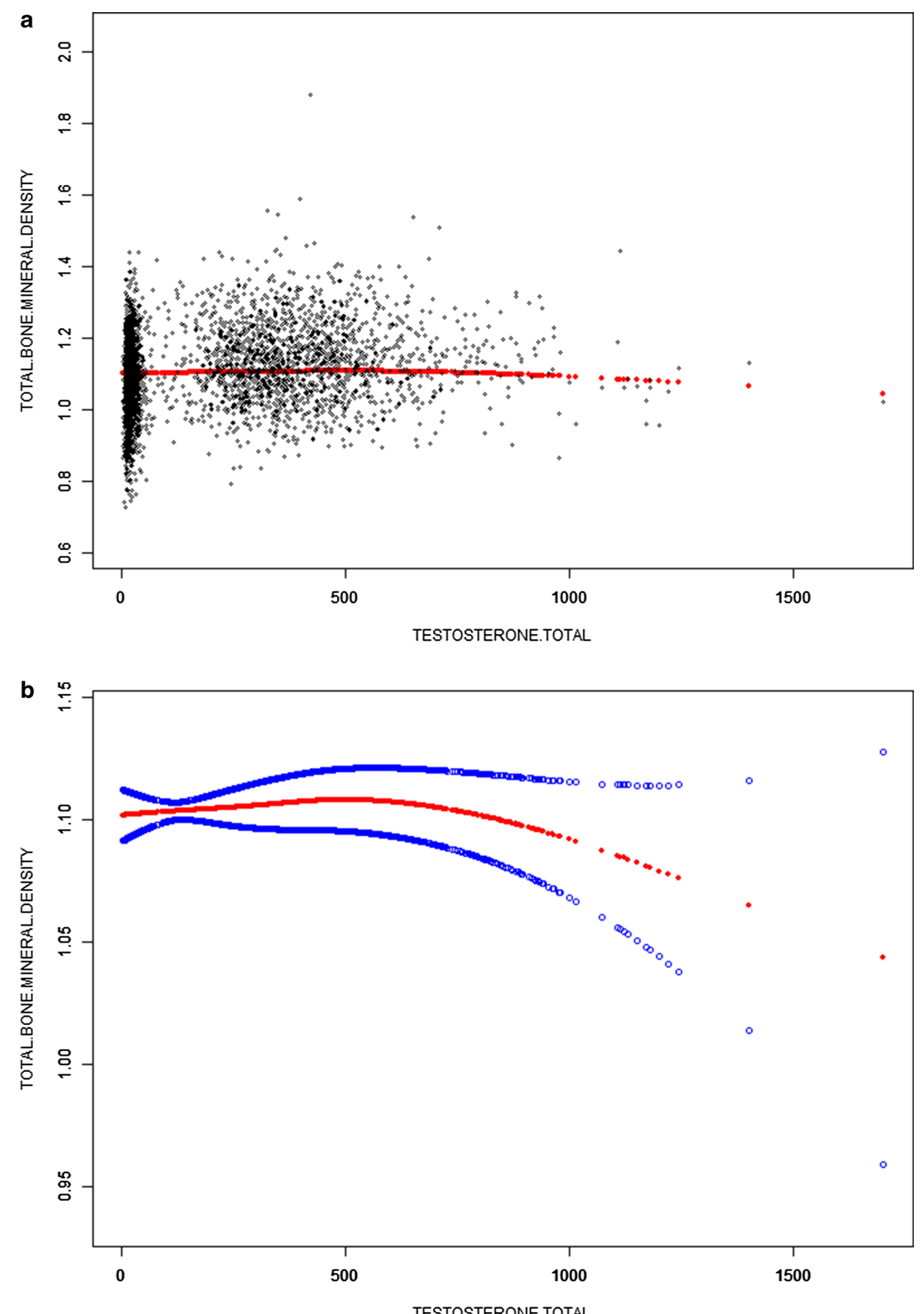

Fig. 1 The association between total testosterone and total BMD. a Each black point represents a sample. $\mathbf{b}$ Solid rad line represents the smooth curve fit between variables. Blue bands represent the $95 \%$ of confidence interval from the fit. Age, sex, race/ethnicity, education, income poverty ratio, total protein, serum phosphorus, and serum calcium were adjusted 


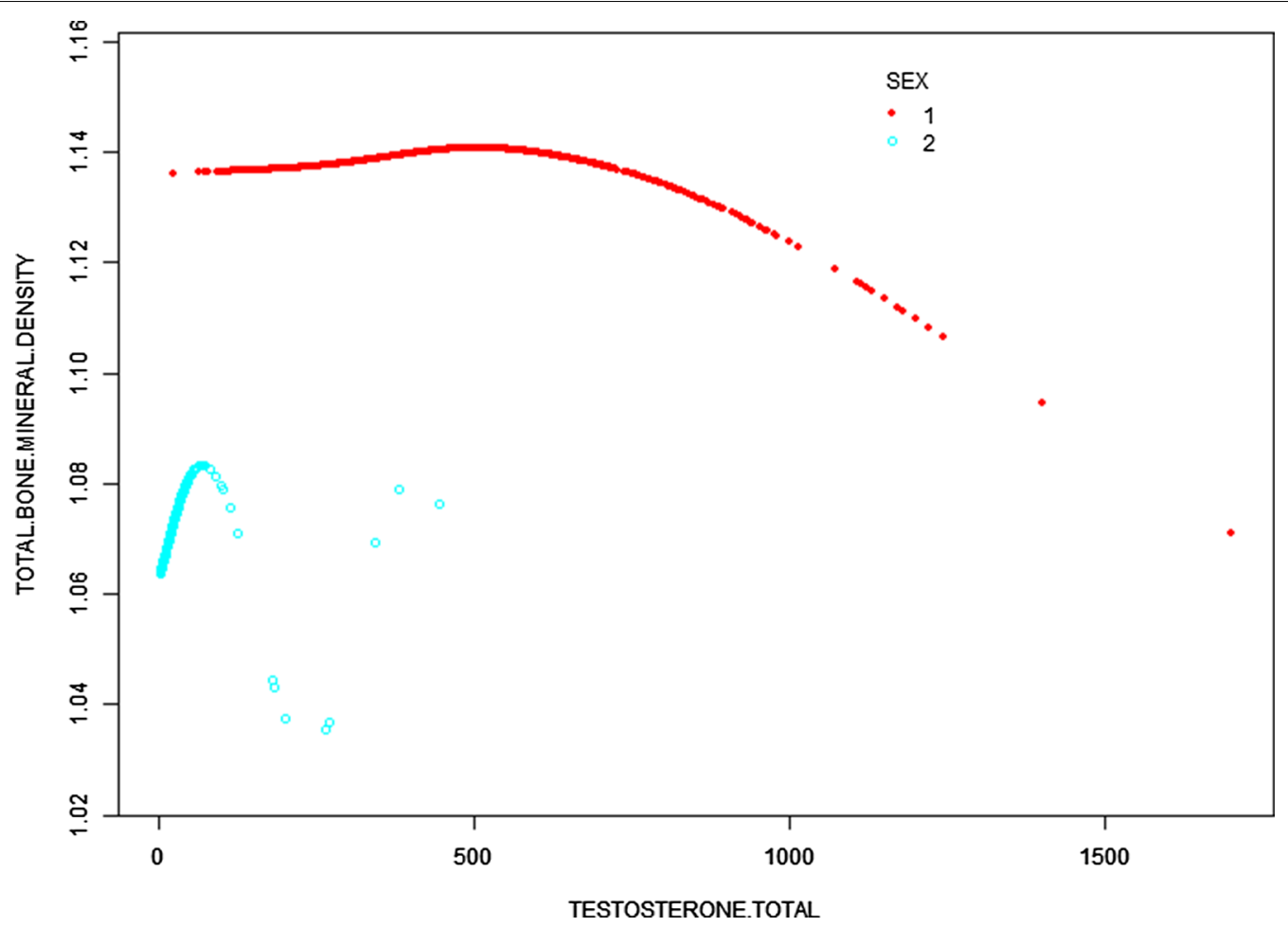

Fig. 2 The association between total testosterone and total BMD stratified by sex. Age, race/ethnicity, education, income poverty ratio, total protein, serum phosphorus, and serum calcium were adjusted

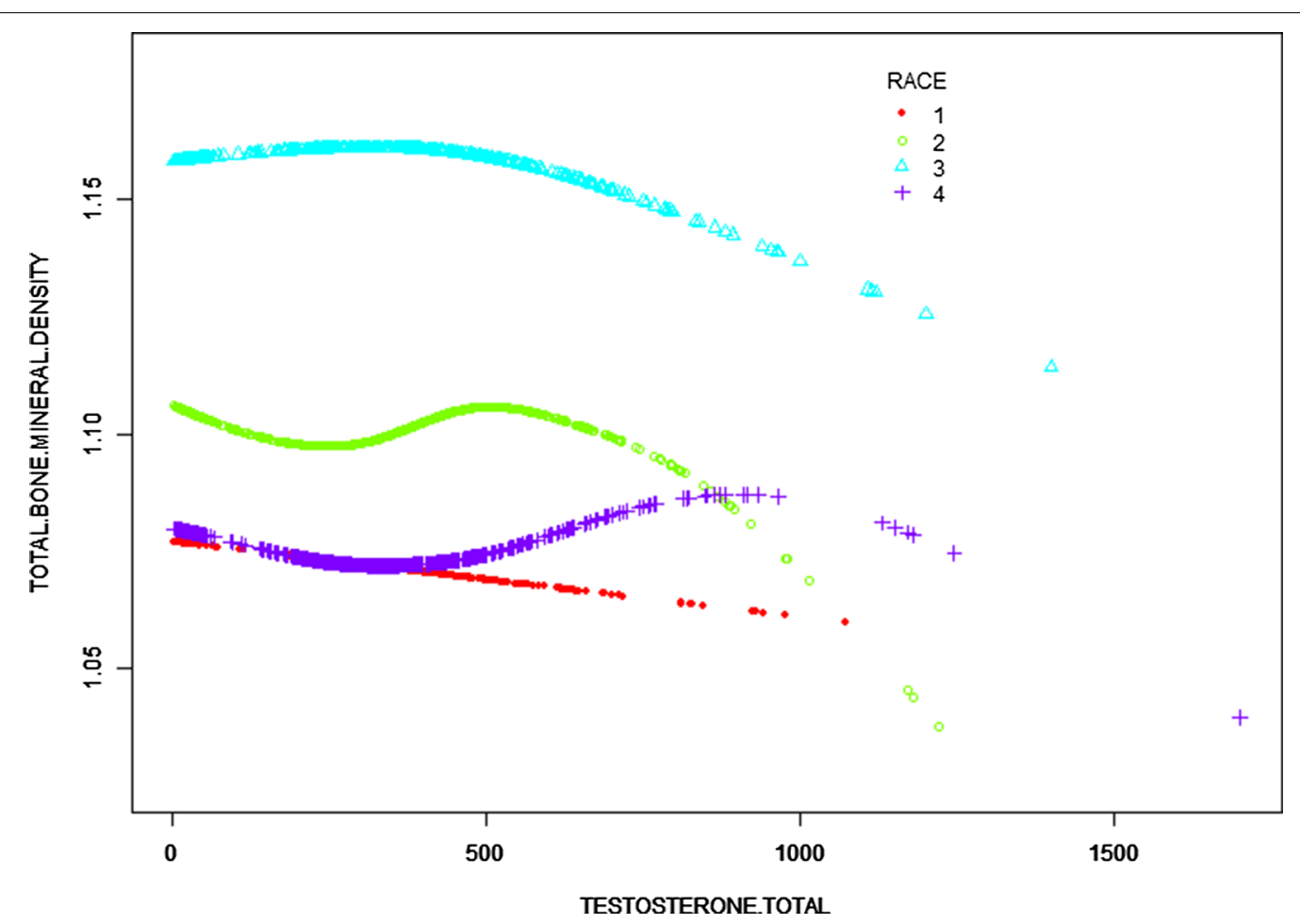

Fig. 3 The association between total testosterone and total BMD stratified by race/ethnicity. Age, sex, education, income poverty ratio, total protein, serum phosphorus, and serum calcium were adjusted 
By contrast, In a study of factors associated with bone mineral density in young male distance runners, resistance training was associated with higher bone mineral density in young adult male distance runners, independent of physiological factors [9]. A study of 199 men with osteoporosis or loss of bone mass found that sex hormone deficiency predicted loss of bone mineral density, with estradiol and testosterone most significantly associated [13]. In a study of 399 men, more than a third of men younger than 50 years with testosterone deficiency and infertility or sexual dysfunction had decreased bone mineral density. Testosterone treatment increased bone mineral density. After testosterone treatment, spinal bone density increased significantly, improving lumbar osteoporosis in men. In this 2-year prospective open-air study, 50 men aged 50 to 65 years who took $50 \mathrm{mg}$ of testosterone gel daily for 12 months significantly improved bone density in the lumbar spine and hip, and improved symptoms of osteoporosis pain [14].

More and more attention is paid to the relationship between total testosterone and markers of bone metabolism. Some scholars believe that the identification of the new determinants of bone mineral density loss in osteoporosis is a field in constant development [15]. Some researchers hope to find a molecular link between total testosterone and osteoblasts and osteoclasts to explain how total testosterone can affect bone mineral density. Researchers used data from 1338 men (25-86 years) in the population-based epidemiological Study of Health in Pomerania for a study [16]. The key finding of the study is the positive association between total testosterone and osteocalcin. Another study examined serum and urinary biochemical parameters of 43 healthy men aged 20-80 years. Univariate analysis of static bone morphometric parameters and biochemical parameters showed that the surface of osteoclasts was significantly correlated with serum total testosterone, indicating that testosterone plays an important role in the pathogenesis of osteoporosis [17].

In this study, we analyzed a representative sample of multiracial populations to better generalize the U.S. population. In addition, such a large sample size allowed us to conduct further subgroup analysis. This is the main advantage of this study. However, these limitations are worth noting. First, because of the cross-sectional design of this study, it is difficult to determine whether there is a causal relationship between total testosterone and total bone mineral density. Second, other confounding factors not included in this study may have influenced the results. For example, men's total testosterone levels are biologically higher than women's. Therefore, differences in sex hormones during adolescent development in adults aged $40-60$ years may be a potential confounding factor to be considered. Therefore, it is necessary to further clarify the role of total testosterone in bone metabolism and conduct longitudinal follow-up studies with large sample size.

In summary, total testosterone level and total BMD differed by sex and race. For American men, the increased total testosterone level would have an adverse effect on bone health with high total testosterone levels $(>500 \mathrm{ng} /$ $\mathrm{dL}$ ), but may have no effect on bone health when total testosterone concentration is lower than $500 \mathrm{ng} / \mathrm{dL}$.

\section{Abbreviations \\ BMD: Bone mineral density; BMI: Body mass index; NHANES: National Health and Nutrition Examination Survey.}

\section{Acknowledgements}

The authors appreciate the time and effort given by participants during the data collection phase of the NHANES project.

\section{Authors' contributions}

WN and WLX contributed to data collection, analysis, and writing of the manuscript. HCC contributed to study design and writing of the manuscript. All authors read and approved the final manuscript.

\section{Funding}

This study received no funding.

\section{Declarations}

Ethics approval and consent to participate

The ethics review board of the National Center for Health Statistics approved all NHANES protocols and written informed consent was obtained from all participants.

\section{Consent for publication}

Not applicable.

\section{Competing interests}

The authors declare that they have no competing interests.

\section{Author details}

${ }^{1}$ Department of Orthopaedics, Zhejiang Chinese Medical University Affiliated Jiangnan Hospital, 152 Yucai Road, Chengxiang Street, Xiaoshan District, Hangzhou City 311200, Zhejiang Province, China. ${ }^{2}$ Zhejiang Chinese Medical University, Hangzhou 310053, Zhejiang, China. ${ }^{3}$ Department of Osteoporosis Care and Control, The First People's Hospital of Xiaoshan District, Hangzhou 311200, Zhejiang, China.

Received: 7 July 2021 Accepted: 10 September 2021

Published online: 18 October 2021

References

1. Hooper DR, Tenforde AS, Hackney AC. Treating exercise-associated low testosterone and its related symptoms. Phys Sportsmed. 2018;46(4):427-34.

2. Cauley JA. Estrogen and bone health in men and women. Steroids. 2015;99(Pt A):11-5.

3. Fink HA, Ewing SK, Ensrud KE, Barrett-Connor E, Taylor BC, Cauley JA, Orwoll ES. Association of testosterone and estradiol deficiency with osteoporosis and rapid bone loss in older men. J Clin Endocrinol Metab. 2006:91(10):3908-15.

4. Snyder PJ, Kopperdahl DL, Stephens-Shields AJ, Ellenberg SS, Cauley JA, Ensrud KE, Lewis CE, Barrett-Connor E, Schwartz AV, Lee DC, et al. Effect of 
testosterone treatment on volumetric bone density and strength in older men with low testosterone: a controlled clinical trial. JAMA Intern Med. 2017;177(4):471-9.

5. Tryniszewski W, Kamiński G, Maziarz Z, Nowak M, Gadzicki M, Radek M. The assessment of testosterone and radioisotopic index of bone metabolism and bone mineral density in men with testosterone deficiency after one year of testosterone therapy. Nucl Med Rev Cent East Eur. 2018;21(1):14-9.

6. Moran JM, Lavado-García JM, Roncero-Martin R, Pedrera-Canal M, Vera V, Fernandez P, Pedrera-Zamorano JD. Testosterone levels and bone mineral density in healthy elderly men. J Am Geriatr Soc. 2015;63(1):206-7.

7. Rodriguez-Tolrà J, Torremadé J, di Gregorio S, Del Rio L, Franco E. Effects of testosterone treatment on bone mineral density in men with testosterone deficiency syndrome. Andrology. 2013;1 (4):570-5.

8. Spitzer M, Huang G, Basaria S, Travison TG, Bhasin S. Risks and benefits of testosterone therapy in older men. Nat Rev Endocrinol. 2013;9(7):414-24.

9. Duplanty AA, Levitt DE, Hill DW, McFarlin BK, DiMarco NM, Vingren JL. Resistance training is associated with higher bone mineral density among young adult male distance runners independent of physiological factors. J Strength Cond Res. 2018:32(6):1594-600.

10. Kim HJ, Koo HS, Kim YS, Kim MJ, Kim KM, Joo NS, Haam JH. The association of testosterone, sex hormone-binding globulin, and insulin-like growth factor-1 with bone parameters in Korean men aged 50 years or older. J Bone Miner Metab. 2017;35(6):659-65.

11. Fink HA, Litwack-Harrison S, Taylor BC, Bauer DC, Orwoll ES, Lee CG, Barrett-Connor E, Schousboe JT, Kado DM, Garimella PS, et al. Clinical utility of routine laboratory testing to identify possible secondary causes in older men with osteoporosis: the Osteoporotic Fractures in Men (MrOS) Study. Osteoporosis Int. 2016;27(1):331-8.

12. Shin J, Sung J, Lee K, Song YM. Genetic influence on the association between bone mineral density and testosterone in Korean men. Osteoporosis Int. 2016;27(2):643-51.

13. Popa FL, Stanciu M, Banciu A, Berteanu M. Association between low bone mineral density, metabolic syndrome and sex steroids deficiency in men. Acta Endocrinologica (Bucharest, Romania: 2005). 2016;12(4):418-22.

14. Kacker R, Conners W, Zade J, Morgentaler A. Bone mineral density and response to treatment in men younger than 50 years with testosterone deficiency and sexual dysfunction or infertility. J Urol. 2014;191(4):1072-6.

15. Scimeca M, Salustri A, Bonanno E, Nardozi D, Rao C, Piccirilli E, Feola $M$, Tancredi V, Rinaldi A, lolascon $G$, et al. Impairment of PTX3 expression in osteoblasts: a key element for osteoporosis. Cell Death Dis. 2017;8(10):e3125

16. Hannemann A, Breer S, Wallaschofski H, Nauck M, Baumeister SE, Barvencik F, Amling M, Schinke T, Haring R, Keller J. Osteocalcin is associated with testosterone in the general population and selected patients with bone disorders. Andrology. 2013;1(3):469-74.

17. Clarke BL, Ebeling PR, Jones JD, Wahner HW, O'Fallon WM, Riggs BL, Fitzpatrick LA. Changes in quantitative bone histomorphometry in aging healthy men. J Clin Endocrinol Metab. 1996;81 (6):2264-70.

\section{Publisher's Note}

Springer Nature remains neutral with regard to jurisdictional claims in published maps and institutional affiliations.
Ready to submit your research? Choose BMC and benefit from:

- fast, convenient online submission

- thorough peer review by experienced researchers in your field

- rapid publication on acceptance

- support for research data, including large and complex data types

- gold Open Access which fosters wider collaboration and increased citations

- maximum visibility for your research: over $100 \mathrm{M}$ website views per year

At BMC, research is always in progress.

Learn more biomedcentral.com/submissions 